\title{
THE CONNECTIVE TISSUE SEPTA IN THE FOETAL HUMAN LUNG*
}

\author{
BY \\ LYNNE REID AND M. RUBINO $\dagger$ \\ From the Institute of Diseases of the Chest, Brompton, London
}

(RECEIVED FOR PUBLICATION SEPTEMBER 1, 1958)

The adult human lung shows considerable variation in the arrangement and density of connective tissue septa (Reid, 1959). As various authors have considered that in the foetal lung the septa are better developed and more easily seen than in the adult (Sappey, 1874-85; Willson, 1928 ; Loosli and Potter, 1951), an examination of the foetal lung was undertaken to discover whether its septal pattern is the same as the adult, or whether the adult arrangement is the result of post-natal modification. Because of its smallness, the whole of the foetal lung can conveniently be examined, giving an idea of the total distribution of septa, which is described in this paper.

\section{Material and Method of Examination}

The lungs studied were from foetuses and babies up to 6 months of age, some born prematurely and some at term. A detailed study was carried out on lungs from an 11-week foetus, together with those from three premature babies whose period of gestation ranged from 24 to 32 weeks, and also from two babies, born at term, making six examples. Details of the periods of gestation, the number of lobes studied, and the plane in which they were sectioned are included in Table I. The age of a foetus was reckoned from values which Mall (recorded by Keith, 1948) has given for the crown to rump length. In addition to the many sections prepared from this material, routine necropsies provided sections from 15 babies under 6 months of age, and a further six foetal lungs were studied. As all these lungs showed a similar arrangement, they will be described as foetal for the purpose of this paper.

The lungs were fixed by intratracheal injection of formol-saline, and, before being embedded in paraffin, were cut into slices (usually three from each lobe), special care being taken to keep the cut surfaces approximately parallel to each other. Since sections at approximately right angles to the septa were most satisfactory for study some lobes were cut horizontally

\footnotetext{
* A communication based on these studies was presented to the Thoracic Society in July, 1956.

$\dagger$ Dr. Rubino, of the Instituto di Patologia Chirurgica, Bari, Italy, took part in this work during his tenure of a bursary from the British Council.
}

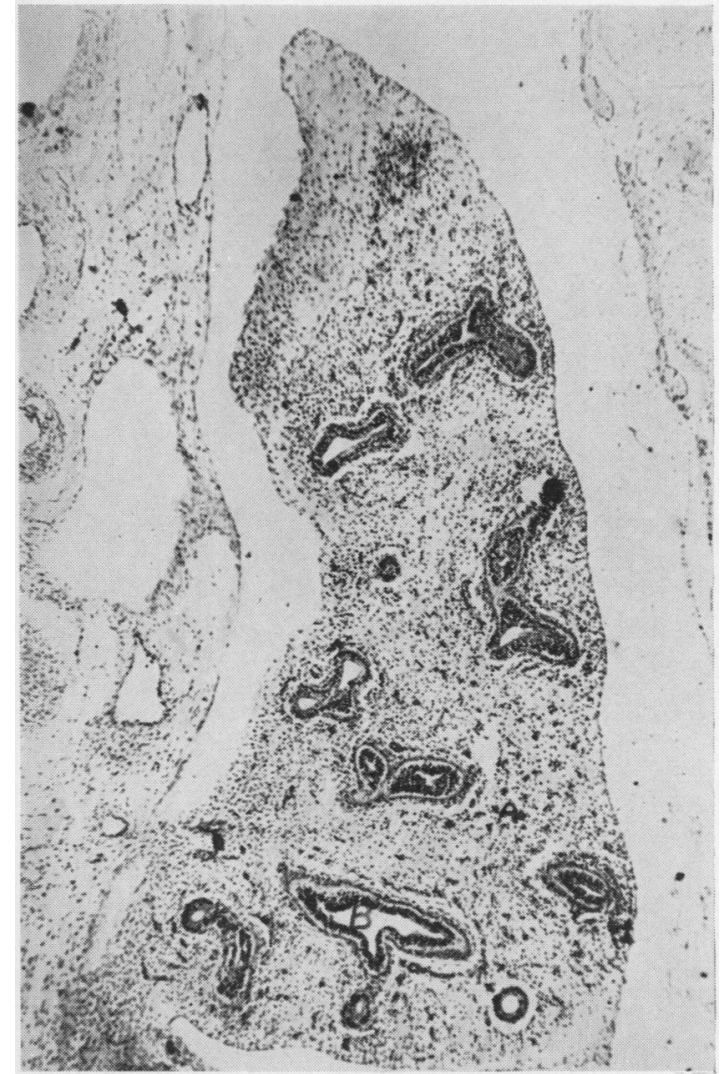

FIG. 1.-Left upper lobe of an 11-week foetus, showing mesenchyme in which bronchial branches lined by epithelium are seen in section. This is the glandular stage, before the development of septa. $(\times 8$.

and others vertically, in either coronal or sagittal planes, so that a variety of sections was available. Details are shown in the right-hand column in Table I. Where the interlobar fissures were incomplete, slices were cut so as to include the region of fusion.

Sections $10 \mu$ thick were cut at varying intervals and mounted serially. In the 11-week foetus every section was stained, and from some of the other specimens 
TABLE I

MATERIAL USED FOR DETAILED HISTOLOGICAL STUDY

\begin{tabular}{|c|c|c|c|}
\hline & Age & Lobes Sectioned* & Plane of Section \\
\hline $\begin{array}{l}1 \\
2\end{array}$ & $\begin{array}{l}11 \text { weeks } \\
24 \text {," }\end{array}$ & $\begin{array}{l}\text { Both lungs } \\
\text { R.U. and R.M. (in part) } \\
\text { Lt.U. and Lt.L. }\end{array}$ & $\begin{array}{l}\text { Frontal } \\
\text { Horizontal } \\
\text { Sagittal }\end{array}$ \\
\hline 3 & $32 \quad$, & $\begin{array}{l}\text { R.U., R.M., R.L. } \\
\text { Lt.U., Lt.L. }\end{array}$ & $\begin{array}{c}\text { Horizontal } \\
\text {, }\end{array}$ \\
\hline 4 & $32 \quad$, & $\begin{array}{l}\text { R.L., R.M., R.L. } \\
\text { Lt.U. } \\
\text { Lt.L. }\end{array}$ & $\begin{array}{l}\text { Frontal } \\
\text { Sagittal }\end{array}$ \\
\hline $\begin{array}{l}5 \\
6\end{array}$ & $\begin{array}{l}\text { Term. (3 days old) } \\
\text { Term (6 months } \\
\text { old })\end{array}$ & $\begin{array}{l}\text { Lt.U. } \\
\text { R.L. }\end{array}$ & $\begin{array}{l}\text { Horizontal } \\
\text { Selected blocks in } \\
\text { various planes }\end{array}$ \\
\hline
\end{tabular}

* Abbreviations used: $\mathrm{R}=$ right. Lt. $=$ left. $\mathrm{U}=$ upper. $\mathrm{L}=$ lower.

over short distances every third section was stained. Although from six lobes sections separated by 100 to $500 \mu$ were examined, it was found that for study of distribution of the septa sections at intervals of 1 to $2 \mathrm{~mm}$. were adequate. The more frequent sections were useful, however, in studying details of the structure of the septa and their relation to the structures they contain. The sections were mostly stained with haematoxylin and eosin, but occasional sections in all the series were stained either by the Verhoeff-van-Gieson or the McManus-periodic-acidSchiff method.

While the septa can be identified macroscopically the most useful method of studying them is in microscopic sections at a low magnification. A bacteriological plate microscope giving a magnification of $\times 10$ for a field $1 \mathrm{~cm}$. in diameter was particularly useful, as the whole section could be quickly scanned. Using document copying paper (as for Fig. 5) it was possible to photograph the sections at a magnification of $\times 12$, a more convenient method of recording appearances than by drawing with a camera lucida. In certain instances line tracings were prepared from these photographs.

TABLE II

NO. OF SEPTA IN SUCCESSIVE HORIZONTAL SLICES OF RIGHT LUNG OF FOETUS OF 32 WEEKS

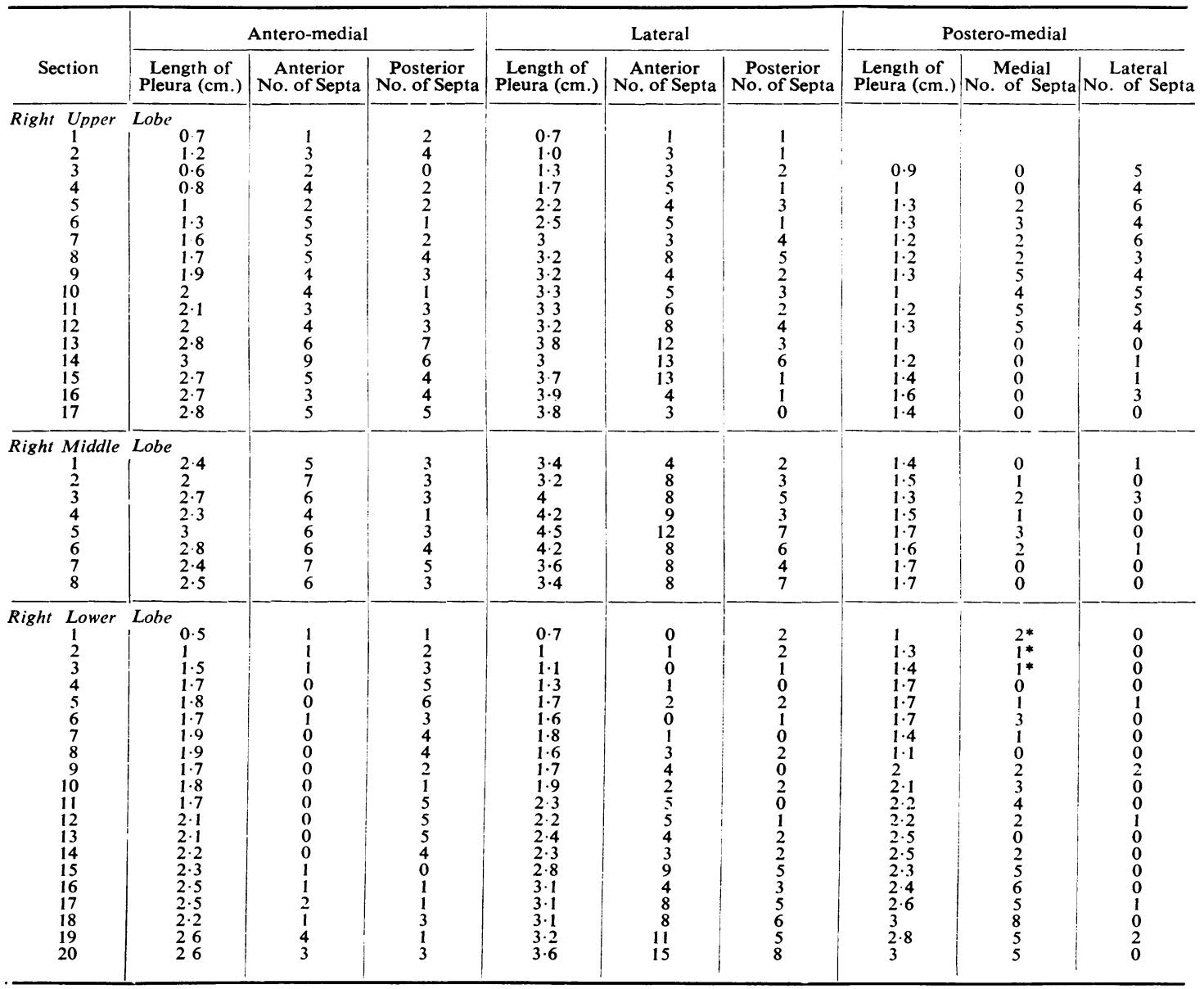


Counting SePta.-Although it was possible by the examination of consecutive sections to gain a general idea of the regional distribution of the septa, counts were made of the actual number which could be identified in order to compare the same region in different lungs and different regions in the same lung. As it is in the subpleural region of both the foetal and the adult lung that septa are present, the deeper part of the lung being almost free, the number of septa in any section was estimated by counting those which reach the pleura. A septum may branch near its origin from the pleura so that it has a forked or triradiate arrangement, but this was counted only once.

The number of septa in sections of two right upper lobes (one is included in Table II) was counted by each of us independently. The results mostly corresponded exactly, and in the occasional instance where they differed it was only by one.

\section{Septa in Developing Human Lung}

DEFINITION.-The term " septum" is used here to describe the sheets of areolar tissue which pass into the substance of the lung from the pleura or from the connective tissue sheaths around bronchi, blood vessels, or lymphatics. Its confusing application to the alveolar wall will not be used.

First Appearance of the Septa as Separate StruCtures.-Before the eighteenth week of foetal life the lung shows the so-called "glandular" phase (Fig. 1), in which bronchial branches appear as spaces lined by epithelium, separated by mesenchyme showing no differentiation to pulmonary structure. At some time between the eighteenth and twentieth weeks
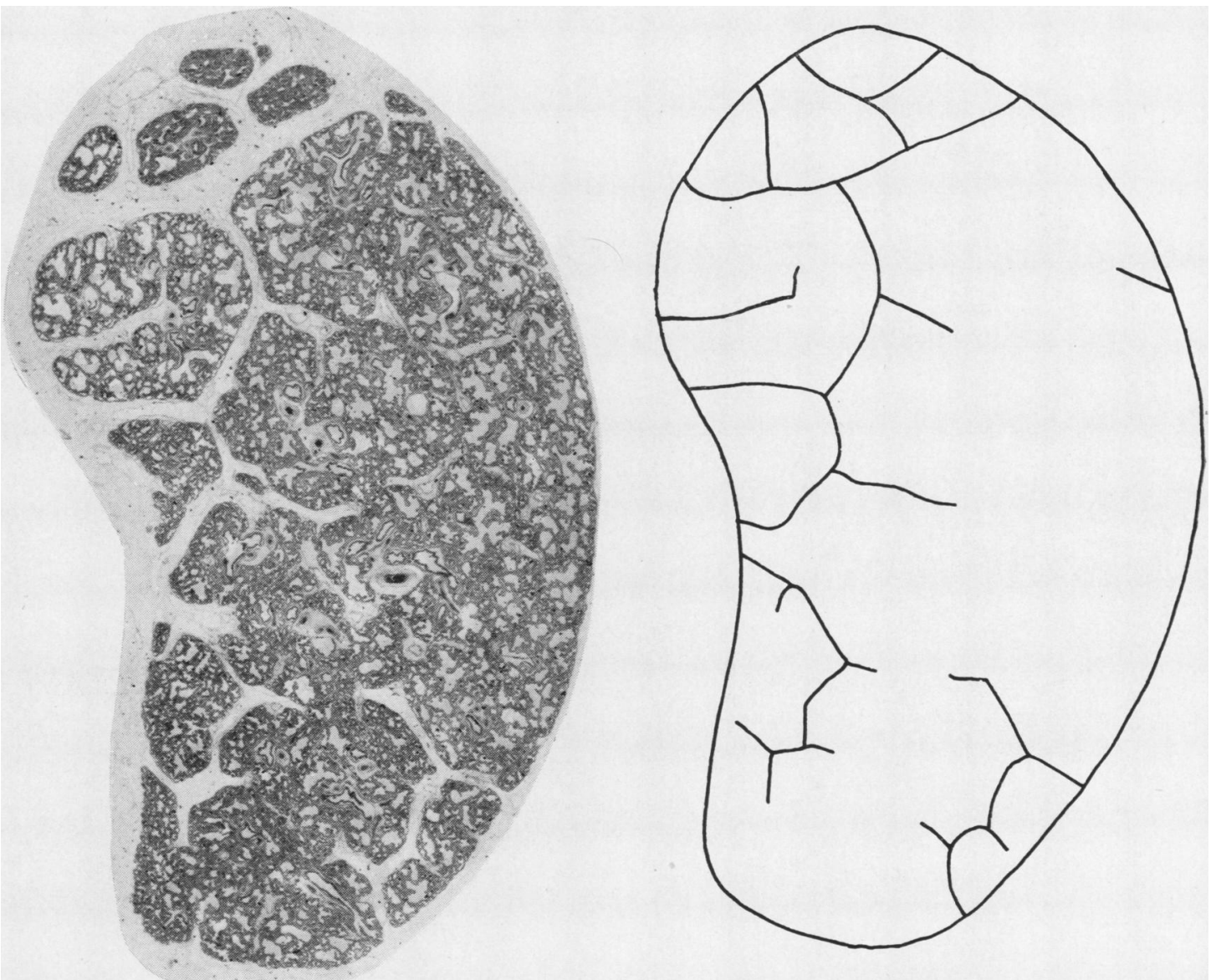

Fig. 2.-Horizontal section of the apex of the right upper lobe, with diagram, of a 24-week foetus, showing few septa over the lateral aspect of the lobe. As the level of this section is more caudal than that illustrated in Fig. 4 it does not includo the septa passing vertically from the apex as seen in Fig. 4. 


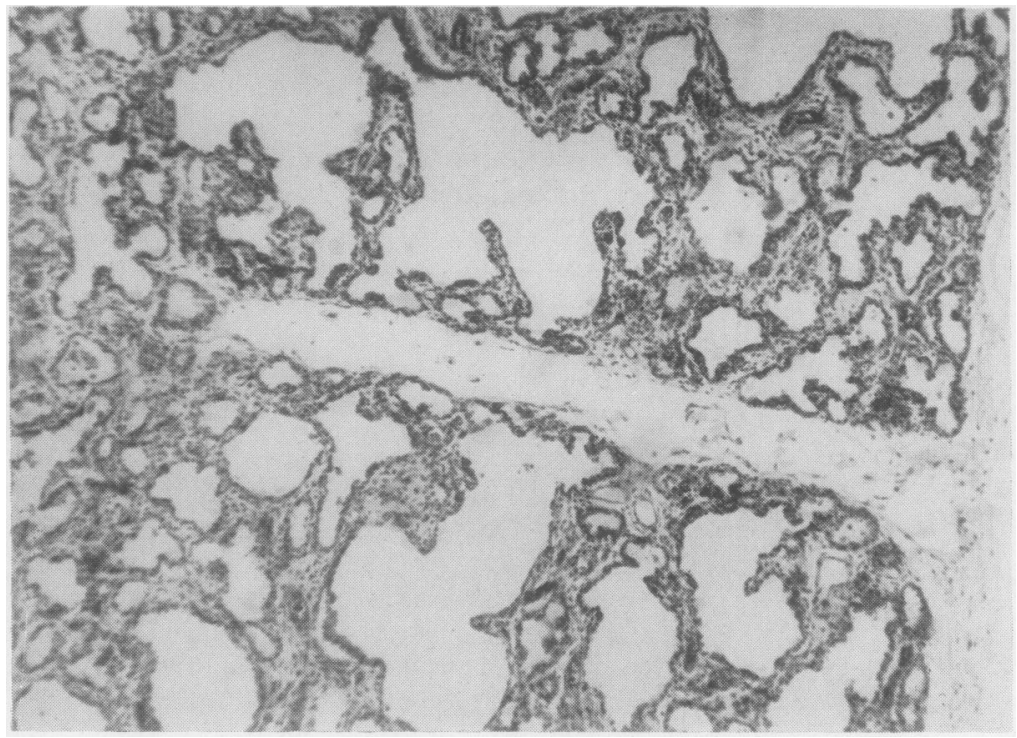

FIG. 3.-Septum arising from the pleura (at right) and passing into the lung, taken from the right middle lobe of the same 24-week foetus as in Fig. 2. Haematoxylin-eosin. $(\times 70$.)
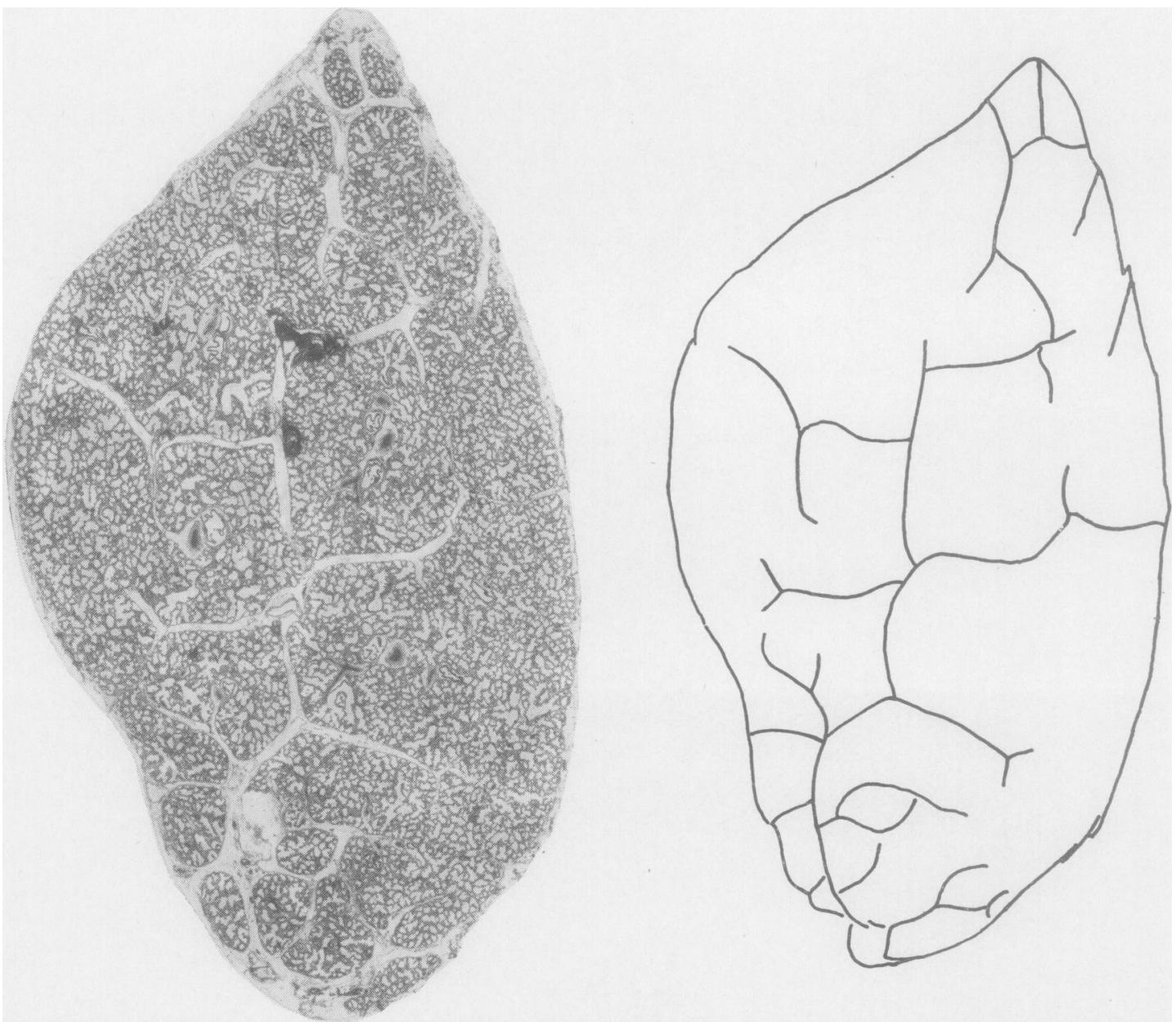

Fig. 4.-Horizontal section with diagram of the apex of the right lung (medial aspect on left hand) of 32-week foetus. The section was rather nearer the apex than that illustrated in Fig. 2. $(\times 8$. 
of intra-uterine development the septa can first be recognized microscopically as separate linear structures. By the twentieth week there is an increase in the number of bronchial generations and in addition the lung takes the structure of the "respiratory" phase-the alveolar spaces and alveolar walls now contain a capillary plexus and the architecture is reminiscent of adult lung (Fig. 3). At certain points sheets of loose areolar tissue, the septa, can be seen. It is already evident that they are incomplete as they neither divide the lung into compartments nor are present uniformly throughout.

Even from macroscopic study of successive sections of the lung it is apparent that these septa, which appear as linear structures in any one section, are sheets of areolar tissue which pass from their bases on the pleura for varying distances into the lung. This distinguishes them from the localized collections of connective tissue which are arranged as a sheath around the blood vessels and bronchi as they pass through the lung. The length of the pleural base of these septa is often as much as $3 \mathrm{~cm}$. in the foetus at term, and although the depth to which the septa penetrate varies, it is usually about $0.5 \mathrm{~cm}$.

Collagen can be identified by the Verhoeff-van Gieson stain in the areolar tissue of the septa from the twentieth week onwards, but even in the 24-week foetus elastic fibres cannot be demonstrated in the walls of the alveoli, although they are present in the walls of the blood vessels. Many large lymphatics lie in these septa.

Positioning of the Foetal and Adult Lung IN THE ThORAX.-Boyden's description (1955) of the surfaces of the lobes in the mature lung can be applied to those in the foetus, for the shape of both is the same. At the same time, the position of the lung surfaces in relation to the chest wall is different, as the heart occupies a relatively larger part of the anterior and central region of the thoracic cage in the foetus than in the adult. The mediastinal surface of the lung in the foetus therefore faces anteriorly as well as medially, but in the adult it is more nearly sagittal and directed medially, the anterior edge having moved forward and nearer the midline. As the distribution of the septa is here described in terms of lung surfaces it is useful to recall that parts of the lung which are posterior in the foetus lie more laterally in the adult, and the part which is described as lateral in the foetus will be antero-lateral in the mature lung.

Numerical Variation of SePta in Different LUNGS.-Exact counts were made of the number of septa both in lungs of different ages and of the same age (an example of the counts obtained from these lobes is included in Table II). A similar pattern of regional distribution at all ages is disclosed, and, generally speaking, although there is some individual variation, there is none that can be particularly ascribed to the age or stage of development of the lung. Illustrations from a 32-week foetus are shown in Figs. 4, 5, 7, and 8, and from a 24-week foetus in Figs. 2, 3, and 9. In different lungs the number of septa is comparable, although in any lung occasional sections may show sudden and wide variation from the number in adjacent sections. Even slight differences in the plane of cutting or in the intervals between sections in relation to a particular specimen may give a seemingly discrepant result.

Distribution of Septa in Relation to the CONTOUR OF THE LUNG.-The detailed description given below of the distribution in different lobes is made with reference to the results in a 32-week foetus, in which all lobes had been serially sectioned in the horizontal plane. The fissure between the left upper and lower lobes was complete, but in the right lung both the major and minor fissures were incomplete, giving some continuity between all three lobes. For the purpose of counting the septa each pleural surface, of which there were usually three in any horizontal section, was divided into two equal parts, this giving six separate counts for each slice (Fig. 6 and Table II). The first column of the table gives the total length of the side in centimetres, the other two show the number of septa in each of the two halves. From these the frequency or concentration of septa can be gauged. This varies considerably, e.g., in section 4 of the right upper lobe the length of the anteromedial edge is about $8 \mathrm{~mm}$., there being four septa in one half, two in the other, making a total of six, while in the fifteenth section of the right lower lobe the same edge of pleura contains only one septum over $23 \mathrm{~mm}$. In any one section, the sum of the numbers of septa in neighbouring halves of the two surfaces which form an edge indicates the concentration of septa at that edge. For instance, the number of septa over the anterior edge of the upper lobe can be found by adding the number in the anterior part of the antero-medial aspect to that in the anterior part of the lateral (regions numbered 1 and 3 in Fig. 6).

The distribution of septa in the lung can be stated in general terms in relation to its contour. The larger and flatter surfaces of the lung are relatively free of septa, which tend to be 


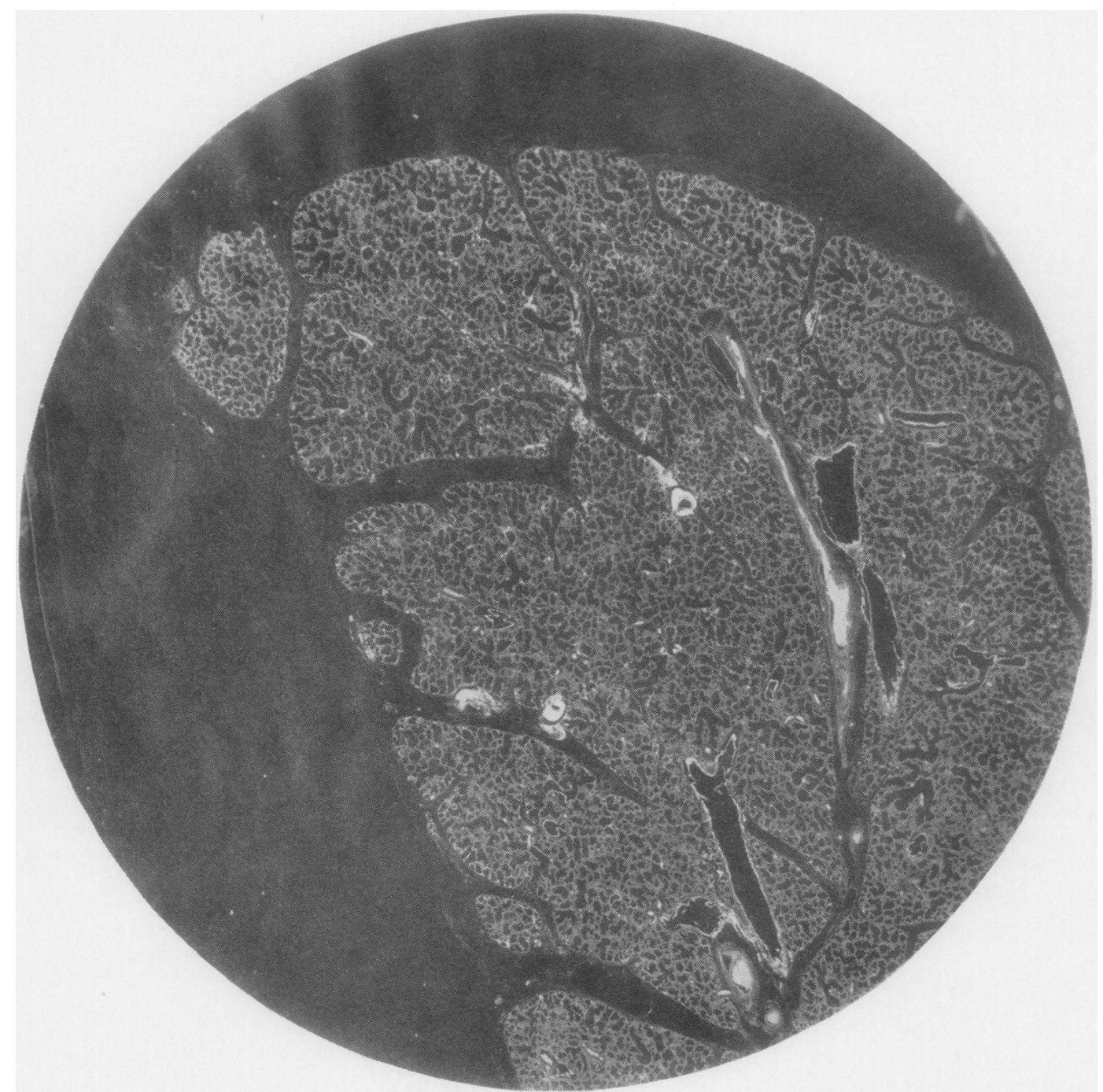

FIG. 5.-Horizontal section from the lung of 32-week foetus through the anterior tip of right middle lobe, showing something of the complexity of the arrangement of the sopta at the angle of a lobe, and of their attachment to bronchi and blood vessels. $(\times 8$.)

concentrated at edges and angles of the lung. For example, the apex and the anterior edge of each of the upper lobes, of the lingula, and of the right middle lobe have a relatively large number of septa, while the fissural surfaces of the lung and the lateral aspect of the lower lobe are almost free of them. The diaphragmatic surface has a relatively large number of septa, however, and is an exception to the general statement that a broad expanse of pleura has relatively few.

Right UPPER LOBE (Fig. 7).-The right upper lobe has four surfaces. In horizontal section it is approximately triangular, the three surfaces being the lateral (or costal), the antero-medial (or anterior mediastinal), and the postero-medial (or posterior mediastinal); the base of the lobe is the fourth or fissural surface. The septa are concentrated at the apex, along the anterior edge of the lung, and the postero-medial ridge; over the central part of the lateral or costal surface they are relatively few and the fissural surface is free of them.

Right Middle Lobe (Fig. 7).-The foetal lobe usually has four surfaces, superior and inferior fissural, costal and medial. In certain foetal lungs part of the inferior fissural surface could be 


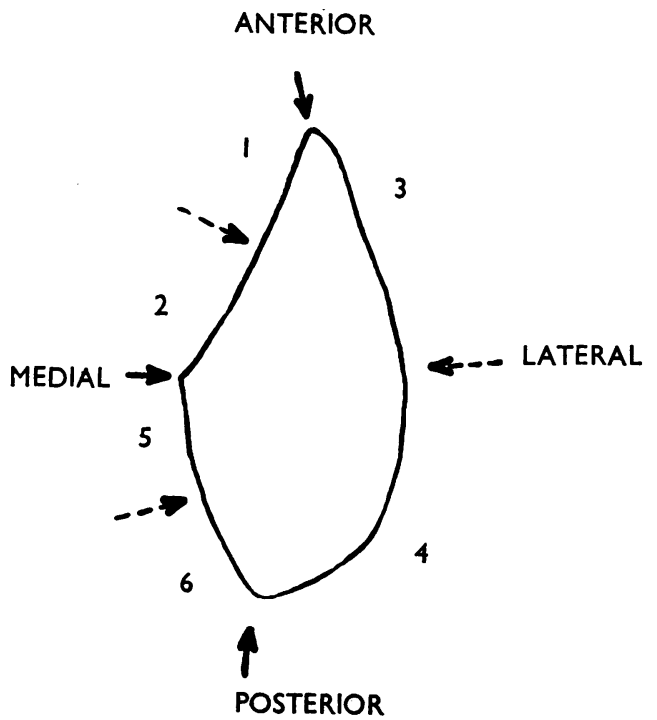

FIG. 6.-Line diagram to illustrate the way a section was divided into six regions for purposes of counting the septa.

recognized as a fifth, the diaphragmatic, which Boyden (1955) described in the adult. The septa are concentrated over the anterior part of the costal surface and the anterior part of the medial surface, that is, on either side of the anterior edge of the lobe. The numbers along the costal edge of the lobe seem high, but this edge is so long that away from the anterior edge the distribution is sparse.

LEFT UPPER LOBE (Fig. 8a).-The left upper lobe also has four surfaces, the fissural, the antero-medial, the postero-medial, and the costal (or lateral). Its shape in terms of surfaces is similar to that of the right upper lobe, but it includes an inferior elongation, the lingula, which even in the foetus varies considerably in size and shape. The arrangement of septa in the left upper lobe resembles that of the right. Septa are concentrated at the apex and over the anterior edge of the lung extending on to the lateral or costal surface for a considerable distance. The fissural surface is free. Thus the lingula has many septa at its anterior edge and tip, but few over its posterior and even fewer over its fissural surfaces.

LOWER LOBE (Fig. 8b).-The costal (or lateral), the medial, the fissural, and the diaphragmatic are the four surfaces of this lobe. When the larger volume of this lobe is considered, the number of septa is low both absolutely and relatively. The highest concentrations are near the hilum, extending posteriorly from it to the costo- vertebral junction, and close to the diaphragm; few are found over the lateral or fissural surfaces. The septa increase in number along the anterior and the costo-vertebral edges towards the diaphragm, from which a considerable number arise, particularly from the anterior two-thirds of the costo-diaphragmatic margin. The costodiaphragmatic edge is as sharp as the anterior edge of the upper lobe which it further resembles in having a large number of septa. The extreme apex of the lower lobe also shows a relatively large number of septa.

Subdivision of the Human Lung by Septa.The illustrations and diagrams (Figs. 2, 4, and 5) give some idea of the way and the extent to which the septa divide the lung. The cross-section of the right upper lobe (Figs. 2 and 4), for example, shows that over the lateral part there is scarcely a septum, so that alveolar tissue is continuous, being interrupted only by lymphatics or blood vessels, but not by discrete sheets of areolar tissue. Examination of a single section suggests that parts of the lung are isolated by septa (as at the anterior tip in Figs. 2 and 4), but serial sections show that this is not so. Even where septa are frequent they are never complete, so that no group of alveoli is ever completely isolated from neighbouring groups.

In the large number of sections studied there was only one instance of a group of alveoli which appeared to be quite isolated by connective tissue. This was in a 32-week foetus and the part in question was rather less than $1 \mathrm{~mm}$. in diameter. Even here there may have been some point at which the septa were not complete, seeing that the sections, although frequent, were not absolutely serial.

Intersegmental Planes of the Lung.-No special features have been demonstrated in the intersegmental planes. The region between the apical segment of the lower lobe and the basal segments were particularly examined, because here there is often an incomplete pleural fissure, but in none of these specimens was this boundary marked by even a well-developed septum. Frequently, the lingula is also separated by a partial fissure. In this site, in several of the specimens, there was well-developed septum which included a large vein, but in none was the septum complete.

INTERLOBAR Planes.-The pleural fissures between lobes are very variable and very often incomplete, as Boyden (1955) has recently emphasized. A particular study was made of the 


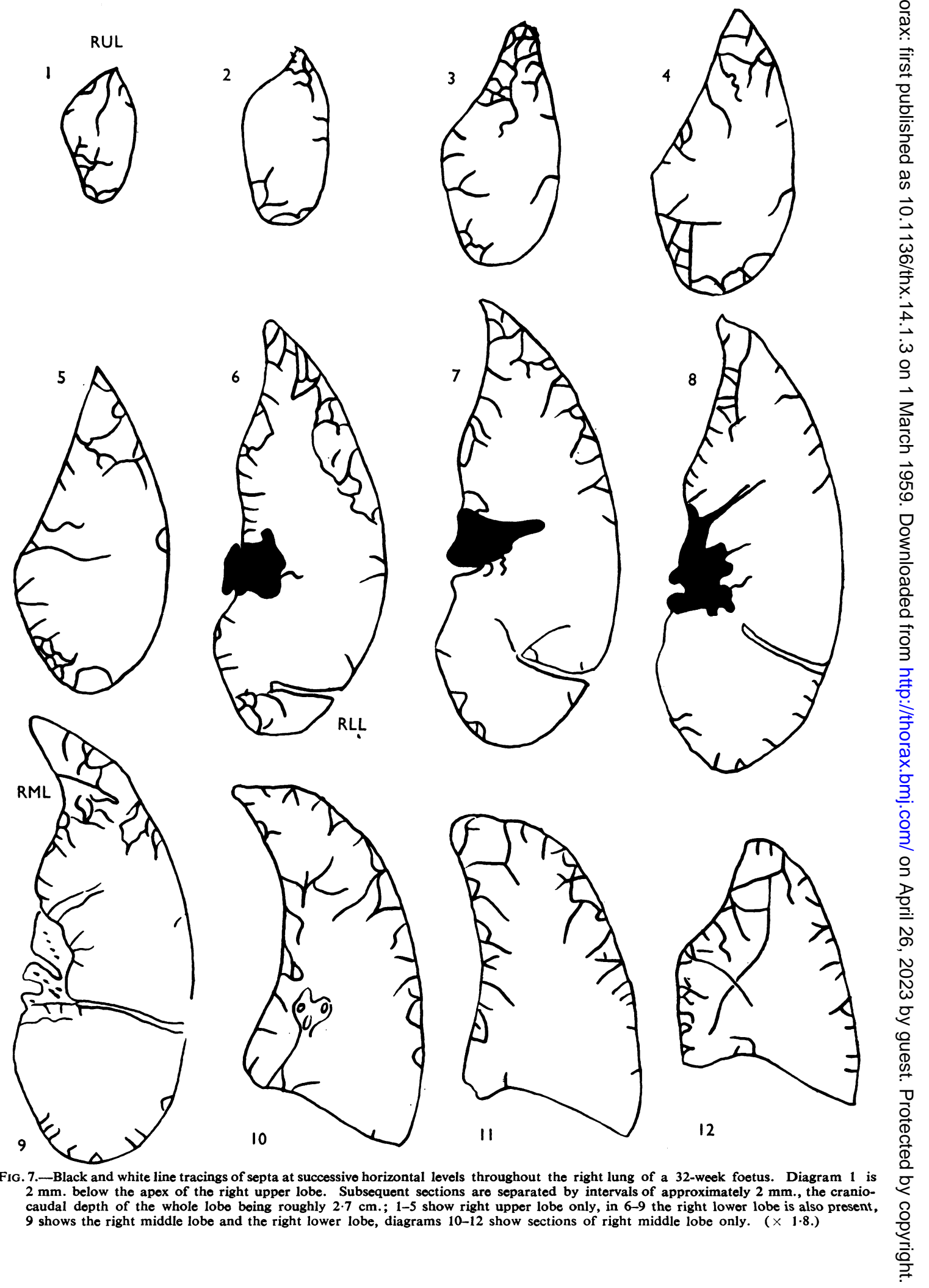



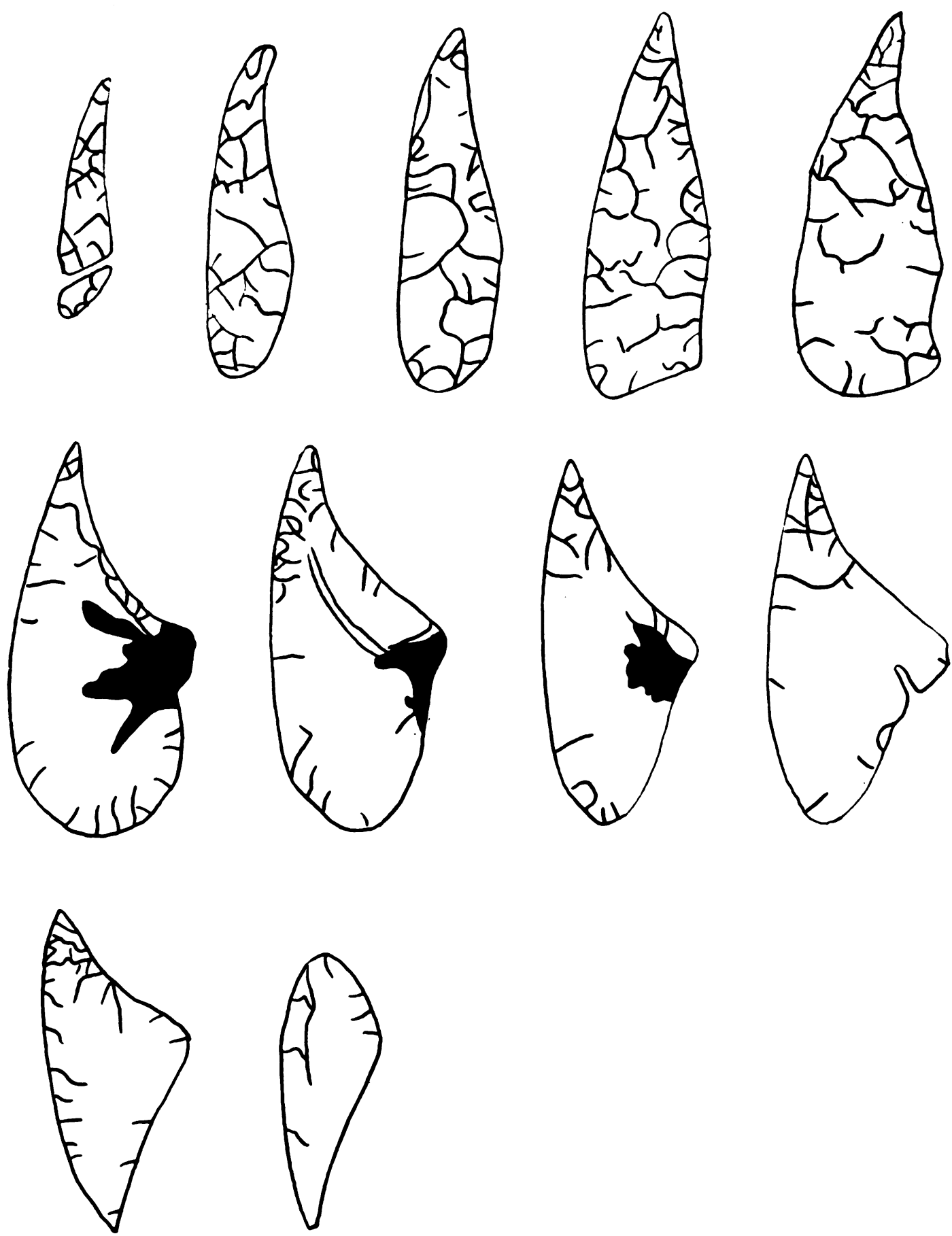

Fig. 8a.-Horizontal sections of the left upper lobe and lingula of a 32-week foetus (as in Fig. 7), the sections represented in these diagrams being separated by intervals of $2 \mathrm{~mm}$. 

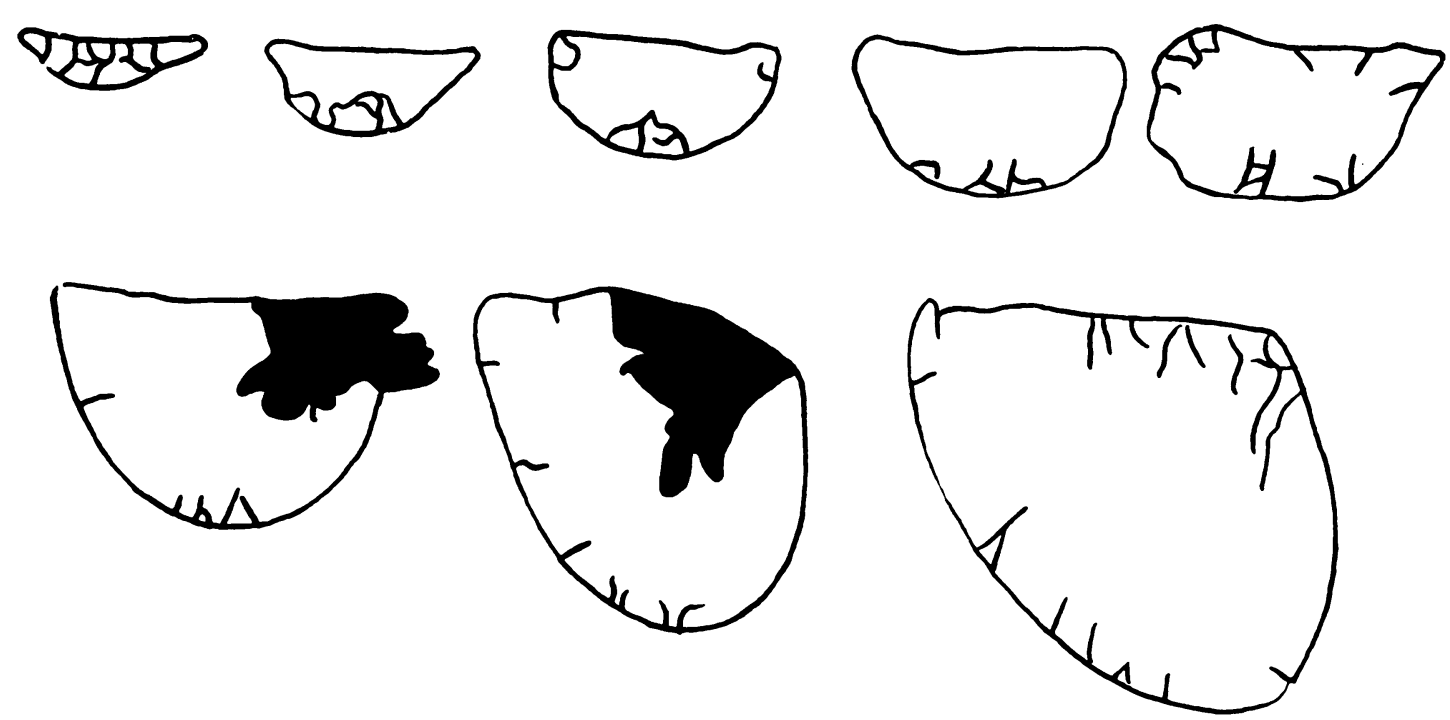

Fig. 8b.-As Fig. 8a: upper part of left lower lobe. $(<1 \cdot 8$.
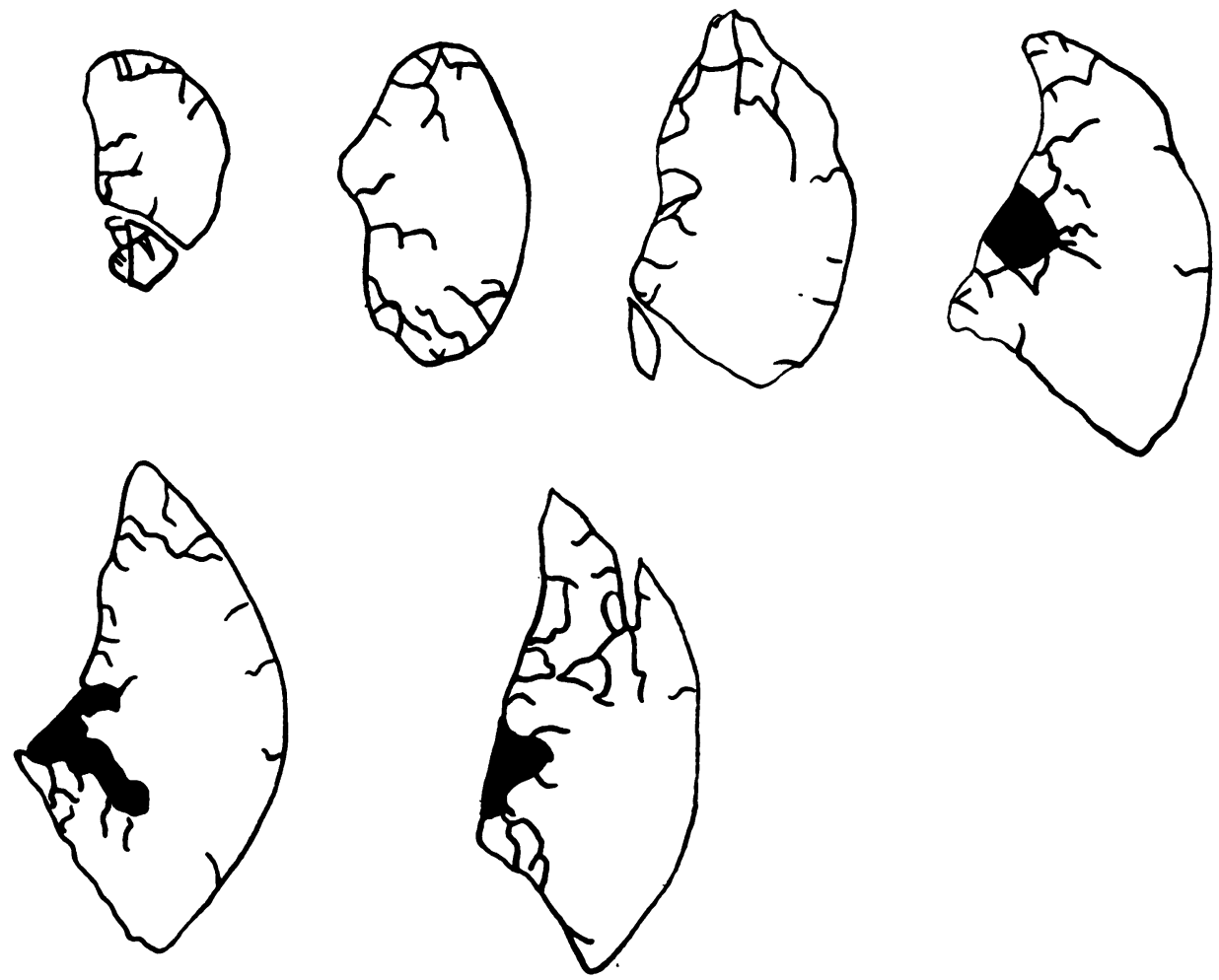

FIG. 9. - Sections from a 24-week foetus of the right upper lobe (the cranio-caudal length bying roughly $1.7 \mathrm{c} \mathrm{n}$.). comparable with those from the 32-week foetus illustrated in Fig. 7, diagrams 1-8. ( $\times 1 \cdot 8$. 
incomplete fissures in these foetal lungs to discover whether a septum continued right to the hilum even if the full thickness of the pleura did not. In three examples there was no septum at all from the edge of the pleura, while in another a septum passed into the lung for a short distance only. In all, therefore, communication between the neighbouring lobes was free.

\section{COMMENT}

The causes of the incompleteness and of the special distribution of the septa in the human lung are not known; their functional significance is important and is discusssed in the paper on the septal arrangement in the adult lung (Reid, 1959). Since septa are present to some extent in all lobes, at both apex and base, the variation in numbers in different parts of the lung cannot be determined by gravitational influences; nor is it the result of the differences in length of particular edges; for instance, the anterior edge of the lower lobe is of approximately the same length as the anterior edge of the upper, and yet in the latter there are many more septa. Distance from the hilum cannot be correlated with numbers of septa, for although the septa are abundant at the tip of the lingula and the costodiaphragmatic rim of the lower lobe, they are also numerous round the hilum. The function of the septa also is not known. Seeing that they are particularly numerous at the edges of the lung (including the costo-fissural margins of the lobes), it may be that they act as supports or ties for lung tissue or, by virtue of their areolar tissue, enable neighbouring parts to move over each other.

\section{SUMMARY}

The distribution of septa in each lobe is described. In general terms, the septa are present in the subpleural region, being numerous over the sharp edges and angles of the lung such as the anterior edge of the upper and middle lobes, the costo-diaphragmatic edge and the costo-vertebral border, absent over the fissural surface, and sparse over the lateral or costal aspects.

This distribution, which is the same as in the adult, is present from the time the septa can first be recognized between the eighteenth and twentieth week of intra-uterine life. No cause for this pattern is known.

Our thanks are due to Dr. R. Seal, pathologist, Sully Hospital, and to Dr. R. M. Haines, Chelsea Hospital for Women, for providing some of the foetal lungs used in this study; and to Mr. D. F. Kemp and Mr. A. C. Curd for the photographs.

\section{REFERENCES}

Boyden, E. A. (1955). Segmental Anatomy of the Lungs. McGraw-Hill, New York.

Keith, A. (1948). Human Embryology and Morphology, 6th ed., p. 83. Arnold, London (Table by Mall).

Loosli, C. G., and Potter, E. L. (1951). Anat. Rec., 109, 320.

Loosli, C. G., and Potter, E. L. (1951). Anat
Reid, Lynne (1959). Thorax, 14, in press.

Sappey, P. C. (1874-85). Anatomie, physiologie, pathologie des vaisseaux lymphatiques. Delahaye, Paris.

Willson, H. G. (1928). Amer. J. Anat., 41, 97. 